\title{
Pain assessment using the NIH Toolbox
}

Karon F. Cook, PhD

Winnie Dunn, PhD,

OTR, FAOTA

James W. Griffith, PhD

M. Tracy Morrison, OTD $\mathrm{R} / \mathrm{L}$

Jennifer Tanquary

Dory Sabata, OTD,

OTR, SCEM

David Victorson, PhD

Leeanne M. Carey, PhD

Joy C. MacDermid,

$\mathrm{BScPT}, \mathrm{MSc}, \mathrm{PhD}$

Brian J. Dudgeon, PhD, OTR

Richard C. Gershon, PhD

Correspondence to

Dr. Cook:

karon.cook@northwestern.edu

\section{ABSTRACT}

Objective: Pain is an important component of health and function, and chronic pain can be a problem in its own right. The purpose of this report is to review the considerations surrounding pain measurement in the $\mathrm{NIH}$ Toolbox, as well as to describe the measurement tools that were adopted for inclusion in the NIH Toolbox assessment battery.

Methods: Instruments to measure pain in the NIH Toolbox were selected on the basis of scholarly input from a diverse group of experts, as well as review of existing instruments, which include verbal rating scales, numerical rating scales, and graphical scales.

Results: Brief self-report measures of pain intensity and pain interference were selected for inclusion in the core $\mathrm{NIH}$ Toolbox for use with adults. A 0 to 10 numerical rating scale was recommended for measuring pain intensity, and a 6-item Patient Reported Outcome Measurement Information System (PROMIS) short form for measuring pain interference. The 8-item PROMIS Pediatric Pain Interference measure was recommended as a supplemental measure. No specific measure was recommended for measuring pain intensity in children.

Conclusions: Core and supplemental measures were recommended for the NIH Toolbox. Additional measures were reviewed for investigators who seek tools for measuring pain intensity in pediatric samples. Neurology ${ }^{\circledR}$ 2013;80 (Suppl 3):S49-S53

\section{GLOSSARY}

DIF = differential item function; IRT = item response theory; $\mathbf{N R S}=$ numerical rating scale; PROMIS $=$ Patient Reported Outcome Measurement Information System; VAS = visual analog scale; VRS = verbal rating scale; WBFPRS = Wong-Baker Faces Pain Rating Scale.

Pain is an important component of health and function. The NIH Toolbox somatosensation team took responsibility for considering the best methods for evaluating pain in the general population. In the International Classification of Functioning, Disability and Health, sensory functions and pain are grouped together as body functions; however, sensation of pain is distinguished from sensory functions such as proprioception or touch, as well as functions related to temperature and other stimuli. ${ }^{1}$ The definition of somatosensory function includes the "detection, discrimination, and recognition" of pain (Dunn et al., this issue). However, pain is more than a biological process and can be integral to function, role participation, and overall quality of life. As such, its assessment often becomes a primary end point in clinical trials and treatment effectiveness studies. This led the Toolbox team to consider pain and its assessment in parallel with somatosensory function and to dedicate separate manuscripts to discussions of pain and somatosensation.

The science of pain measurement has benefited from recent advances in measurement approaches and applications. ${ }^{2-4}$ The field of outcomes research has well-developed, self-reported pain measures that have been validated in a range of acute and chronic medical conditions. For this reason, the team chose not to develop new pain measures but to adopt existing instruments that would add to the battery of tests included in the NIH Toolbox. In this article, we describe the importance of pain to the assessment of health and discuss its multidimensional nature. We

From the Northwestern University (K.F.C., J.W.G., D.V., R.C.G.), Chicago, IL; University of Kansas Medical Center (W.D., M.T.M., J.T., D.S.), Kansas City; National Stroke Research Institute (L.M.C.), Heidelberg; LaTrobe University (L.M.C., J.C.M.), Melbourne, Australia; and McMaster University (B.J.D.), Hamilton, Canada.

Go to Neurology.org for full disclosures. Funding information and disclosures deemed relevant by the authors, if any, are provided at the end of the article. 
identify pain subdomains of particular interest to users of the NIH Toolbox and review current strategies for measuring those subdomains in adults and in children. This review is intended to provide users with a context for understanding the measurement of pain subdomains. Our recommendations for the NIH Toolbox core and supplemental measures of pain are summarized.

PAIN AND HEALTH ASSESSMENT Pain has been defined as an "unpleasant sensory and emotional experience associated with actual or potential tissue damage, or described in terms of such damage. ${ }^{" 5,6}$ The International Association for the Study of Pain has called unrelieved pain "a major global healthcare problem."

Experiences and assessments of pain are often characterized as acute, chronic, or persistent. ${ }^{8}$ Acute pain comes on abruptly and lasts a relatively short time. Such pain serves as a warning of an injury or sudden illness and may be mild or severe. ${ }^{9}$ Chronic pain extends beyond the expected period of healing, often designated as persisting 6 months or more. A national survey estimated the point prevalence of chronic pain at $>30 \%$, with half of these reporting daily pain and $32 \%$ reporting 3 -month average pain $\geq 7$ on a scale of 0 to $10 .{ }^{10}$ Not only is pain highly prevalent, its impact on quality of life is far-reaching. Pain interferes with sleep, makes activities of daily living more difficult, limits social engagement, and is financially burdensome to individuals and their families (see, for example, references 11-15). Furthermore, pain causes changes in neural function that outlast the precipitating disease or injury. Although typically triggered by injury or disease, chronic pain "becomes independent; it takes on a life of its own." ${ }^{16}$ Thus, pain has been described as "a disease in its own right." ${ }^{16}$ The prevalence, impact, and psychological and physiologic consequences of unrelieved chronic pain make it a critical domain in the assessment of health.

Because pain has a variety of origins and expressions, it is best described as multidimensional. ${ }^{17}$ Subdomains include pain intensity and temporal patterns, description and localization, and interference with quality of life, affect, and behavior. A full assessment of pain might include measures of each of these subdomains. For the purposes of the NIH Toolbox, investigators focused on the 2 most frequently assessed subdomains: pain intensity and pain interference. ${ }^{18}$ Below we summarize common strategies for the measurement of pain intensity and interference within adult and pediatric populations.

PAIN INTENSITY Measuring pain intensity of adults. Pain intensity, defined as the "magnitude of experienced pain," ${ }^{19}$ is a narrow construct often measured using a 1-item scale. To measure pain intensity of adults, the most common strategies are verbal rating scales (VRSs), numerical rating scales (NRSs), visual analog scales (VASs), and graphical scales. With VRSs, participants select from among pain descriptors (e.g., mild, moderate, severe). VASs present a line on which respondents mark the point they believe most descriptive of their pain. The line has verbal descriptors, "anchors," at the ends (e.g., "no pain" or "extreme pain"). Sometimes descriptors between anchors are included. NRSs ask respondents to pick a number that represents their pain level (e.g., 0-10). Graphical scales represent graduated levels of pain as drawings (e.g., faces) that express increasing levels of distress. Participants select the picture that best represents their level of pain. Graphical scales have verbal or numerical descriptors as anchors and may have one or more descriptors between anchors.

An extensive review on behalf of the European Palliative Care Research Collaborative examined 54 published studies that compared at least 2 of 3 different categories of scales (i.e., VRSs, VASs, NRSs) in acute or chronic pain. ${ }^{20}$ Across the 54 studies, 131 unique measures were cataloged: 59 VASs, 39 VRSs, and 33 NRSs. Most of the reviewed studies recommended no particular category of pain-intensity scaling. Of those that did, 3 suggested a scale from a category other than NRSs, VRSs, or VASs; 11 recommended using NRSs; 7, VRSs; and 4, VASs. Correlations are typically high between scores from different kinds of pain-intensity measures, ${ }^{20}$ but substantial nonequivalence between individual scores has been documented, ${ }^{21-24}$ and this nonequivalence in scores varied in direction..$^{22,23}$

Measuring pain intensity of children. Even more challenging than measuring the pain of adults is measuring pain intensity experienced and reported by children. Strategies include self-report, physiologic indicators, and behavioral measures (including proxy report). ${ }^{25-27}$ These different approaches produce nonequivalent results that only weakly correlate with each other. ${ }^{26}$ The weak associations suggest that they may be assessing distinct constructs. ${ }^{26}$

As with adults, self-report is accepted as the "gold standard" for measuring the pain intensity of children. ${ }^{25,28}$ Graphical scales are arguably less abstract than NRS and VAS measures and often are used for measuring children's pain intensity. There are a number of "faces pain scales" that include drawings of faces to suggest graduated levels of distress (e.g., smiling face at one end; face with tears at the other). Tomlinson et al. ${ }^{28}$ conducted a review of self-reported pain-intensity measures for children and found that children prefer faces scales to other single-item measures. In their review, the Wong-Baker Faces Pain Rating Scale (WBFPRS) ${ }^{29}$ was preferred by children in studies that compared more than one faces scale. 
NIH Toolbox pain-intensity measures. For measuring the pain intensity of adults, the NIH Toolbox adopted a single-item measure for inclusion within its core battery of assessments. The item, "In the past 7 days, how would you rate your pain on average?" is scored on a 0 to 10 NRS in which $0=$ no pain and $10=$ worst imaginable pain. The 0 to 10 NRS is frequently used in clinical studies, and its validity has been demonstrated empirically. ${ }^{19}$ Adding to its usefulness are estimations made within different clinical populations, based on the 0 to 10 scale, of cut-scores for different levels of pain (e.g., mild, moderate, severe). ${ }^{30-32}$ However, this recommendation is qualified by the empirical findings of nonequivalence between individual scores. ${ }^{21-24}$ No measure of pain intensity can fully capture individuals' experiences of pain.

Although the NIH Toolbox only addressed assessment of average pain intensity, it is important to note that "worst pain" also has been suggested as a clinical trial end point. ${ }^{33,34}$ Worst pain may be measured by substituting the phrase "on average" with a phrase such as "at its worst."

For the measurement of children's pain intensity, no specific supplemental measure was identified for the NIH Toolbox. Although research indicates that children prefer a faces scale, ${ }^{28}$ the WBFPRS has weaknesses. The anchor faces of the WBFPRS (a smiley face and a face with tears) may confound affect with pain intensity, especially in younger children. ${ }^{28}$

PAIN INTERFERENCE MEASUREMENT Pain interference may be thought of as a functional consequence of pain intensity. There is substantial empirical and clinical evidence that the 2 are distinct constructs and that each provides valuable information. ${ }^{18}$ Pain intensity is a relatively narrow domain, but pain interference is broader, multifaceted, and associated with pain disability. The subdomains typically tracked by self-reported pain interference measures include impact on physical function, work, recreation, social activities, family roles, activities of daily living, and sleep.

Measuring pain interference in adults. There are many published measures of pain interference for use in adult populations (see, for example, references 35-38). However, with few exceptions, ${ }^{3,35,39}$ pain interference measures have been developed using classic test theory approaches. Compared with classic psychometric approaches, newer strategies such as item response theory (IRT) allow for finer-grade evaluations of measures. Psychometric assessments are made at the individual item level, not at the scale level as with classic test theory. Furthermore, the precision of scores at different levels of pain interference can be assessed with IRT methods by calculating scale information. ${ }^{40}$ The Patient Reported Outcome Measurement Information
System (PROMIS) initiative applied IRT methods in developing the PROMIS Pain Interference item bank. ${ }^{3}$ As described on the PROMIS Web site (http://www. nihpromis.org), "The pain interference item bank measures the self-reported consequences of pain on relevant aspects of one's life. This includes the extent to which pain hinders engagement with social, cognitive, emotional, physical, and recreational activities ...”

Measuring pain interference in children. Although substantial psychometric attention has been given to the measurement of children's pain intensity, the same is not true of the measurement of children's pain interference. Two exceptions are the Child Activity Limitations Interview $^{41}$ and the PROMIS Pediatric Pain Interference Scale. ${ }^{42}$ An advantage of the PROMIS scale over the Child Activity Limitations Interview is the fact that it was developed using modern psychometric methods (IRT), and the items of the bank were tested for differential item function (DIF) between boys and girls of differing ages. DIF exists when, after holding level of pain interference constant, the probabilities of different responses to an item vary by subgroup. DIF is a threat to measurement validity because the trait being measured should drive how respondents answer a question, not their membership in a particular demographic or clinical subgroup. An 8-item subscale assesses pain impact on children's sleep, attention, mobility (e.g., walking, running, standing), ability to have fun, schoolwork, and affect (e.g., anger when in pain). A recently published study with 8- to 17-year-old children with cancer found evidence for the feasibility and validity of the PROMIS pediatric measures, including the PROMIS Pain Interference measure.

NIH Toolbox pain interference measures. For the measurement of pain interference in adults, the NIH Toolbox adapted the PROMIS Pain Interference v1.0-Pain Interference 6a (https://www.assessmentcenter.net). The 6 items of this short form ask, "How much did pain interfere with: a) your day to day activities, b) work around the home, c) your ability to participate in social activities, d) your household chores, e) the things you usually do for fun, and f) your enjoyment of social activities?" Each item is scored from 1 to 5 , where $1=$ not at all, $2=$ a little bit, $3=$ somewhat, $4=$ quite a bit, and $5=$ very much. The item set in short form 6 a includes 6 of the 10 most "discriminating" items in the item bank; that is, the items that best distinguish among different levels of pain interference. Items with greater discrimination yield more precision in estimating individuals' pain interference levels.

The NIH Toolbox adopted the PROMIS Pediatric Pain Interference measure for use in measuring selfreported pain interference in children. To date, clinical validity of this measure has been evidenced in children 
aged 8 to 17 years. Future studies need to evaluate whether the measure retains its validity and feasibility in younger clinical populations.

CONCLUSION In this article, we present a context for understanding the importance of pain and review strategies for its measurement. Two measures were adopted into the NIH Toolbox core battery for adults: a 0 to 10 NRS for measuring pain intensity and a 6 item PROMIS Pain Interference short form. The PROMIS Pediatric Pain Interference is included as a supplemental measure for measuring children's pain interference. No particular scale for measuring pain intensity in pediatric populations was recommended.

\section{AUTHOR CONTRIBUTIONS}

Dr. Cook: manuscript concept and design. Dr. Dunn, Dr. Griffith, Dr. Morrison, Dr. Tanquary, Dr. Sabata, Dr. Victorson: domain conceptualization and critical review of the manuscript for important intellectual content. Dr. Carey: study supervision, domain conceptualization and critical review of the manuscript for important intellectual content, domain conceptualization, and critical review of the manuscript for important intellectual content. Dr. MacDermid, Dr. Dudgeon, Dr. Gershon: study supervision, domain conceptualization and critical review of the manuscript for important intellectual content.

\section{STUDY FUNDING}

This study is funded in whole or in part with Federal funds from the Blueprint for Neuroscience Research, NIH, under contract no. HHS-N-260-2006-0000-7-C.

\section{DISCLOSURE}

K. Cook has received financial support from Center for Psychiatric Rehabilitation Boston University, InvivoData, Xenoport, BrightOucome, the NIH, Veteran's Affairs Research and Development, National Institute on Disability and Rehabilitation Research (NIDDR), and Agency for Healthcare Research and Quality (AHRQ). In addition to Toolbox, Dr. Cook receives other funding from NIH (5RC1NR011804-02 and 1 U5AR057943-01). She also is currently supported by grants from NIDDR (H133B090024) and AHRQ (1R03HS020700-01). W. Dunn is the author of the Sensory Profile measures, which are published by Pearson Inc. Pearson Inc. owns the copyright on these tests, and Dr. Dunn receives a royalty when they are sold. J. Griffith has received financial support from NorthShore University HealthSystem, the Cleveland Clinic Foundation/Teva Neurosciences, Inc., Ironwood Pharmaceuticals, Inc. and Forest Laboratories, Inc., the $\mathrm{NIH}$, the Department of Defense (DOD)-United States Army, and the FWO, Belgium. In addition to NIH Toolbox funding, he receives funding from the NIH for other research (grant U01 DK082342). He has also been a paid consultant to Dr. Kathryn Grant of DePaul University, and maintains a clinical psychology practice for which he bills for his services. T. Morrison, J. Tanquary, and D. Sabata report no disclosures. D. Victorson holds stock options in Eli Lilly and Company, received an honoraria for serving on the Steering Committee of the Reeve Neuro-Recovery Network, was funded by NIH contracts HHSN265200423601C and HHS-N-260-200600007-C and grants R01HD054569-02NIDRR, 1U01NS056975-01, R01 CA104883, received support from the American Cancer Society (national and Illinois Division) for research in prostate cancer, received institutional support from NorthShore University HealthCare System for research in prostate cancer, received institutional support from the Medical University of South Carolina for sarcoidosis research, and received institutional support from the Northwestern Medical Faculty Foundation for urology research. L. Carey is supported by an Australian Research Council Future Fellowship (FT0992299) and was previously supported by a National Health and Medical Research Council of Australia Career Development Award (307905). Dr. Carey is an expert consultant for the NIH Toolbox Project. J. MacDermid and B. Dudgeon report no disclosures. R. Gershon has received personal compensation for activities as a speaker and consultant with Sylvan Learning, Rockman, and the American Board of Podiatric Surgery. He has several grants awarded by NIH: N01-AG-6-0007, 1U5AR057943-01, HHSN260200600007, 1U01DK082342-01, AG-260-06-01, HD05469; NINDS: U01 NS 056 975 02; NHLBI K23: K23HL085766; NIA: 1RC2AG036498-01; NIDRR: H133B090024; OppNet: N01-AG-6-0007.

Received June 6, 2012. Accepted in final form September 27, 2012.

\section{REFERENCES}

1. Cieza A, Stucki G, Weigl M, et al. ICF core sets for chronic widespread pain. J Rehabil Med 2004;36:63-68.

2. Revicki DA, Chen WH, Harnam N, et al. Development and psychometric analysis of the PROMIS pain behavior item bank. Pain 2009;146:158-169.

3. Amtmann D, Cook KF, Jensen MP, et al. Development of a PROMIS item bank to measure pain interference. Pain 2010;150:173-182.

4. Cella D, Riley W, Stone A, et al. The Patient-Reported Outcomes Measurement Information System (PROMIS) developed and tested its first wave of adult self-reported health outcome item banks: 2005-2008. J Clin Epidemiol 2010;63:1179-1194.

5. IASP Task Force on Taxonomy. Part III: pain terms-a current list with definitions and notes on usage. In: Merskey H, Bogduk N, editors. Classification of Chronic Pain, 2nd ed. Seattle: IASP Press; 1994:209-214.

6. IASP Task Force on Taxonomy. IASP Taxonomy [online]. Available at: http://www.iasp-pain.org/AM/Template.cfm? Section=Pain_Definitions. Accessed February 8, 2013.

7. International Association for the Study of Pain. Unrelieved pain is a major healthcare problem [online]. Available at: http://www.iasp-pain.org/AM/Template.cfm?Section $=$ Home\& Template $=/ C M /$ ContentDisplay.cfm\&ContentID $=2908$. Accessed April 13, 2012.

8. Institute of Medicine of the National Academies. Relieving Pain in America: A Blueprint for Transforming Prevention, Care, Education, and Research. Washington, DC: The National Academies; 2011.

9. Berry PH, Dahl JL. The new JCAHO pain standards: implications for pain management nurses. Pain Manag Nurs 2000;1:3-12.

10. Johannes CB, Le TK, Zhou X, Johnston JA, Dworkin RH. The prevalence of chronic pain in United States adults: results of an Internet-based survey. J Pain 2010;11:1230-1239.

11. Mystakidou K, Parpa E, Tsilika E, et al. The relationship of subjective sleep quality, pain, and quality of life in advanced cancer patients. Sleep 2007;30:737-742.

12. Schirbel A, Reichert A, Roll S, et al. Impact of pain on health-related quality of life in patients with inflammatory bowel disease. World J Gastroenterol 2010;16:3168-3177.

13. Stewart WF, Ricci JA, Chee E, Morganstein D, Lipton R. Lost productive time and cost due to common pain conditions in the US workforce. JAMA 2003;290: 2443-2454.

14. Ramstad K, Jahnsen R, Skjeldal OH, Diseth TH. Parentreported participation in children with cerebral palsy: the contribution of recurrent musculoskeletal pain and child mental health problems. Dev Med Child Neurol 2012;54: 829-835.

15. Institute of Medicine (US) Committee on Advancing Pain Research, Care, and Education. Relieving Pain in America: A Blueprint for Transforming Prevention, Care, Education, 
and Research. Washington, DC: The National Academies Press; 2012.

16. Niv D, Devor M. Chronic pain as a disease in its own right. Pain Pract 2004;4:179-181.

17. Merskey H, Bogduk N, editors. Classification of Chronic Pain, 2nd ed.Seattle, WA: IASP Press; 1994.

18. Fayers PM, Hjermstad MJ, Klepstad P, et al. The dimensionality of pain: palliative care and chronic pain patients differ in their reports of pain intensity and pain interference. Pain 2011;152:1608-1620.

19. Jensen MP, Karoly P. Measurement of cancer pain via patient self-report. In: Chapman CR, Foley KM, editors. Current and Emerging Issues in Cancer Pain: Research and Practice. New York: Raven Press; 1993:193-218.

20. Hjermstad MJ, Fayers PM, Haugen DF, et al. Studies comparing numerical rating scales, verbal rating scales, and visual analogue scales for assessment of pain intensity in adults: a systematic literature review. J Pain Symptom Manage 2011;41:1073-1093.

21. Carpenter JS, Brockopp D. Comparison of patients' ratings and examination of nurses' responses to pain intensity rating scales. Cancer Nurs 1995;18:292-298.

22. Collins SL, Moore RA, McQuay HJ. The visual analogue pain intensity scale: what is moderate pain in millimetres? Pain 1997;72:95-97.

23. Ekblom A, Hansson P. Pain intensity measurements in patients with acute pain receiving afferent stimulation. J Neurol Neurosurg Psychiatry 1988;51:481-486.

24. Heikkinen K, Salantera S, Kettu M, Taittonen M. Prostatectomy patients' postoperative pain assessment in the recovery room. J Adv Nurs 2005;52:592-600.

25. von Baeyer CL, Spagrud LJ. Systematic review of observational (behavioral) measures of pain for children and adolescents aged 3 to 18 years. Pain 2007;127:140-150.

26. Walco GA, Conte PM, Labay LE, Engel R, Zeltzer LK. Procedural distress in children with cancer: self-report, behavioral observations, and physiological parameters. Clin J Pain 2005;21:484-490.

27. Zhou H, Roberts P, Horgan L. Association between self-report pain ratings of child and parent, child and nurse and parent and nurse dyads: meta-analysis. J Adv Nurs 2008;63:334-342.

28. Tomlinson D, von Baeyer CL, Stinson JN, Sung L. A systematic review of faces scales for the self-report of pain intensity in children. Pediatrics 2010;126:e1168-e1 198.

29. Wong DL, Baker CM. Pain in children: comparison of assessment scales. Pediatr Nurs 1988;14:9-17.

30. Gerbershagen HJ, Rothaug J, Kalkman CJ, Meissner W. Determination of moderate-to-severe postoperative pain on the numeric rating scale: a cut-off point analysis applying four different methods. Br J Anaesth 2011;107:619626.

31. Kapstad H, Hanestad BR, Langeland N, Rustoen T, Stavem K. Cutpoints for mild, moderate and severe pain in patients with osteoarthritis of the hip or knee ready for joint replacement surgery. BMC Musculoskelet Disord 2008;9:55.

32. Li KK, Harris K, Hadi S, Chow E. What should be the optimal cut points for mild, moderate, and severe pain? J Palliat Med 2007;10:1338-1346.

33. Farrar JT, Pritchett YL, Robinson M, Prakash A, Chappell A. The clinical importance of changes in the 0 to 10 numeric rating scale for worst, least, and average pain intensity: analyses of data from clinical trials of duloxetine in pain disorders. J Pain 2010;11:109-118.

34. Koller A, Miaskowski C, De Geest S, Opitz O, Spichiger E. Supporting self-management of pain in cancer patients: methods and lessons learned from a randomized controlled pilot study. Eur J Oncol Nurs 2013;17:1-8.

35. Becker J, Schwartz C, Saris-Baglama RN, Kosinski M, Bjorner JB. Using item response theory (IRT) for developing and evaluating the Pain Impact Questionnaire (PIQ-6TM). Pain Med 2007;8:S129-S144.

36. Cleeland CS, Ryan KM. Pain assessment: global use of the Brief Pain Inventory. Ann Acad Med Singapore 1994;23: 129-138.

37. Kerns RD, Turk DC, Rudy TE. The West Haven-Yale Multidimensional Pain Inventory (WHYMPI). Pain 1985; 23:345-356.

38. Pollard CA. Preliminary validity study of the pain disability index. Percept Mot Skills 1984;59:974.

39. Lai JS, Dineen K, Reeve BB, et al. An item response theory-based pain item bank can enhance measurement precision. J Pain Symptom Manage 2005;30:278-288.

40. Hays RD, Bjorner JB, Revicki DA, Spritzer KL, Cella D. Development of physical and mental health summary scores from the patient-reported outcomes measurement information system (PROMIS) global items. Qual Life Res 2009;18:873-880.

41. Palermo TM, Lewandowski AS, Long AC, Burant CJ. Validation of a self-report questionnaire version of the Child Activity Limitations Interview (CALI): the CALI21. Pain 2008;139:644-652.

42. Varni JW, Stucky BD, Thissen D, et al. PROMIS Pediatric Pain Interference Scale: an item response theory analysis of the pediatric pain item bank. J Pain 2010;11:11091119. 


\title{
Neurology
}

\author{
Pain assessment using the NIH Toolbox \\ Karon F. Cook, Winnie Dunn, James W. Griffith, et al. \\ Neurology 2013;80;S49-S53 \\ DOI 10.1212/WNL.0b013e3182872e80
}

This information is current as of March 11, 2013

\section{Updated Information \& Services}

\section{References}

Citations

Subspecialty Collections

Permissions \& Licensing

Reprints including high resolution figures, can be found at: http://n.neurology.org/content/80/11_Supplement_3/S49.full

This article cites 35 articles, 1 of which you can access for free at: http://n.neurology.org/content/80/11_Supplement_3/S49.full\#ref-list-1

This article has been cited by 3 HighWire-hosted articles: http://n.neurology.org/content/80/11_Supplement_3/S49.full\#\#otherarti cles

This article, along with others on similar topics, appears in the following collection(s):

\section{All Pain}

http://n.neurology.org/cgi/collection/all_pain

Information about reproducing this article in parts (figures,tables) or in its entirety can be found online at:

http://www.neurology.org/about/about_the_journal\#permissions

Information about ordering reprints can be found online:

http://n.neurology.org/subscribers/advertise

Neurology ${ }^{\circledR}$ is the official journal of the American Academy of Neurology. Published continuously since 1951, it is now a weekly with 48 issues per year. Copyright @ 2013 American Academy of Neurology. All rights reserved. Print ISSN: 0028-3878. Online ISSN: 1526-632X.

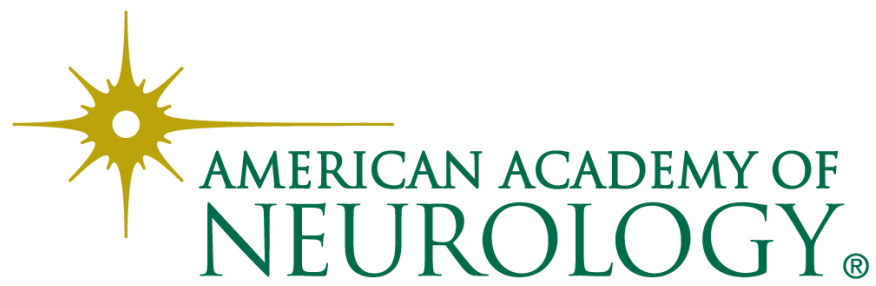

